\title{
Predictive power of the Triticum root elongation test for the assessment of novel anti-proliferative therapies
}

\author{
OCTAVIAN TUDOREL OLARU ${ }^{1}$, ANCA ZANFIRESCU ${ }^{1}$, GEORGE MIHAI NITULESCU ${ }^{1}$, \\ GEORGIANA NITULESCU ${ }^{1}$, CRISTINA ELENA DINU-PIRVU ${ }^{1}$, VALENTINA ANUTA ${ }^{1}$, \\ ARISTIDIS TSATSAKIS ${ }^{2}$, DEMETRIOS A. SPANDIDOS ${ }^{3}$, DENISA MARGINA $^{1}$ and OANA CRISTINA SEREMET ${ }^{1}$ \\ ${ }^{1}$ Faculty of Pharmacy, 'Carol Davila’ University of Medicine and Pharmacy, 020956 Bucharest, Romania; \\ ${ }^{2}$ Department of Forensic Sciences and Toxicology, Faculty of Medicine, and ${ }^{3}$ Laboratory of Clinical Virology, \\ School of Medicine, University of Crete, 71003 Heraklion, Greece
}

Received March 4, 2019; Accepted May 2, 2019

DOI: $10.3892 / \mathrm{ijmm} .2019 .4192$

\begin{abstract}
The use of alternative techniques to reduce the number of animals used in anticancer research is an issue of current interest. The aim of this study was to validate the use of a simple and efficient alternative tool for the assessment of the potential of novel anti-proliferative agents. A set of 20 compounds with various mechanisms were tested in the Triticum aestivum root elongation assay, using aminophylline as negative control. Hierarchical cluster analyses were performed using the furthest neighbor method based on Euclidean distance measure, and the compounds were statistically analyzed in reference to their anti-proliferative pattern registered in the NCI60 human tumor cell line anticancer drug screen. A correlation between the Triticum test results and the NCI60 anti-proliferative profile was made for a number of human cells that we defined as the Triticum cell panel. Linear equations were computed that can be used to transform the inhibitory effect measured in any future Triticum assay in order to predict the effect on particular human cells. Of the tested anti-proliferative agents, methotrexate, colchicine, cantharidin, cisplatin and verapamil produced a growth inhibition over $50 \%$. On the whole, the findings of this study suggest that the Triticum test can be used to detect several types of anti-proliferative mechanisms, particularly those targeting
\end{abstract}

Correspondence to: Professor George Mihai Nitulescu, Faculty of Pharmacy, 'Carol Davila' University of Medicine and Pharmacy, 6 Traian Vuia, 020956 Bucharest, Romania

E-mail: nitulescu_mihai@yahoo.com; george.nitulescu@umfcd.ro

Professor Aristidis Tsatsakis, Department of Forensic Sciences and Toxicology, Faculty of Medicine, University of Crete, Voutes, 71003 Heraklion, Greece

E-mail: tsatsaka@uoc.gr

Key words: phytotoxicity assessment, plant growth dynamics, NCI60 cell line panel, screening oncology compounds, tubulin inhibitors, spindle assembly inhibitors, mitotic arrest tubulin, rendering it a useful tool with which to identify novel mitotic spindle inhibitors.

\section{Introduction}

Experimental animal data are essential to the development of novel therapeutic compounds, and the observations are commonly assumed to be predictive of biological responses in humans. However, ethical issues lead to the need for reducing the number of animals used in preclinical testing; therefore, there is a stringent need for the development of alternative assays so as to allow a selection of compounds for further preclinical development. Operational primary screens enable researchers to substitute a significant proportion of animal research (1). This also applies for anticancer compounds, for which animal testing is still prevalently used. In the case of anticancer compounds, it is important to have validated methods for assessing the anti-proliferative effects, before moving into the next stage, the preclinical one (2).

The functional similarities among living organisms can be a very useful background for generating biological information. The extrapolation of results among species can offer valuable information, particularly in the case of a toxic effect (3). Some non-animal tests have proven themselves valuable for pre-screening compounds, and thus reducing the number of animals used in consequent research. For example, the Ames test, using strains of the Salmonella typhimurium to determine whether chemicals cause DNA mutations, has been successfully validated and is widely employed as pre-screening to reduce rodent testing for cancer-causing compounds (4).

Other useful methods are phytobiological tests, which examine phytotoxicity. Successfully used to evaluate the environmental effects in contaminated soils $(5,6)$ and wastewater $(7,8)$, and to assess the cytotoxicity of pollutants, such as arsenic (9), pesticides (10) and herbicides (11), they measure the delay of seed germination, the inhibition of plant growth or any adverse effects on plants caused by specific substances (5). In this study, we wished to determine the relevance of this when testing anticancer compounds. We wished to determine whether it is possible to establish a direct association between the impairment of plant growth and the anti-proliferative effects 
of cytostatics, thus using phytobiological tests as pre-screening assays for such substances.

Several higher plants can be used for the study of root elongation, ranging from monocotyledons, such as Triticum aestivum $(12,13)$, Agropyrum repens (14), Allium cepa (15,16), Panicum miliaceum, Avena sativa (17), to dicotyledons e.g., Vicia faba (18), Lycopersicon esculentum (19), Lactuca sativa (20), Cucurbita pepo (21), Raphanus sativus (17), Phaseolus radiatus (13). A previous study demonstrated that monocots exhibit a greater sensitivity (6).

These plants have been employed as instruments for the screening of the toxicity of bioactive compounds. Tests using these plants are very easy to perform, and have a low cost, are efficient and present good correlations with other tests $(6,22)$ connected to cytotoxicity and genotoxicity (23). Root growth is regulated by two processes which are closely linked, cell division and cell expansion. The inhibition of root elongation can be achieved either by cytotoxic agents that inhibit the cell cycle in different phases or by inhibitors of cell expansion (24). However, we wished to determine whether the Triticum aestivum root elongation test can be used as an effective method for the biological evaluation of novel potential anti-proliferative agents and whether a plant-based assay can predict mammalian efficacy.

It is likely that anti-proliferative drugs can produce the same effect in the Triticum assay as in higher living organisms, since a significant number of oncogenic signal transduction pathways are highly conserved in living organisms (25). For this purpose, in this study, we examined the effect produced on the root growth of wheat seeds by a number of known cytotoxic substances with various structures and mechanisms of action. To better understand the limitations of the test, the results were classified and correlated with the anti-proliferative profiles on human tumor cell lines, using the data provided by the Developmental Therapeutics Program (DTP) of the National Cancer Institute (NCI) (26). The NCI60 fingerprint of anti-proliferative effects can be used to elucidate the mechanisms of action, or to identify similar known compounds (27). The versatility and usefulness of chemoinformatic and bioinformatics analyses based on the NCI60 profiles has been demonstrated in various studies (28-31).

The aim of this study was to determine whether the phytobiological toxicity screening test could provide information on the anti-proliferative effects in human cells, since this effect is regulated by similar processes that are highly conserved in the cell division process of all eukaryotic organisms. Root elongation is frequently used for the assessment of cytotoxicity, due to its several already mentioned advantages. The purpose of this study was to establish its limitations and to validate its use, thus providing an additional tool for the screening of both natural and new synthesized compounds with potential anti-proliferative effects.

\section{Materials and methods}

Reagents and chemicals. All reagents and solvents were purchased from commercial suppliers. The compounds used for screening were purchased from Sigma-Aldrich and were as follows: Albendazole (54965-21-8), aminophylline
(317-34-0), busulfan (55-98-1), cantharidin (56-25-7), chlorambucil (305-03-3), cisplatin (15663-27-1), colchicine (64-86-8), cyclophosphamide (6055-19-2), epirubicin hydrochloride (56390-09-1), fluorouracil (51-21-8), hydroxyurea (127-07-1), imatinib mesylate (220127-57-1), indole-3-acetic acid (87-51-4), irinotecan hydrochloride (100286-90-6), mercaptopurine (6112-76-1), methotrexate (133073-73-1), paclitaxel (33069-62-4), podophyllotoxin (518-28-5), quinine hydrochloride dehydrate (6119-47-7) and verapamil hydrochloride (152-11-4).

Compound preparation. Triticum aestivum (Boema cultivar), supplied by SC Adaflor SRL was selected as the test plant. Dry caryopses were soaked for $24 \mathrm{~h}$ in distilled water and 20 caryopses for each concentration were equally distributed on filter paper disks in Petri dishes of $90 \mathrm{~mm}$ diameter and treated with $5 \mathrm{ml}$ of each test solution. The bioassay was performed at $25 \pm 1^{\circ} \mathrm{C}, 75 \%$ relative humidity in the absence of light, in a plant growth chamber (MLR-351H; Sanyo). All compounds were dissolved in dimethyl sulfoxide (DMSO) and diluted with sterilized distilled water until the concentration of DMSO was $1 \%$. Each compound was tested in duplicate at concentrations ranging from 0.1 to $500 \mu \mathrm{M}(0.1,0.5,1,5$, $10,50,100$ and $500 \mu \mathrm{M})$ depending on the solubility or the results of preliminary tests. A negative control sample was prepared with aminophylline due its inactivity on all NCI60 cell lines, as evidenced by the data downloaded from the NCI website (https://dtp.cancer.gov/databases_tools/default.htm). A solvent control with $1 \%$ DMSO in distilled water was used. Indole-3-acetic acid is a well-known plant hormone (32) and was used as positive control. The length of the embryonic root was measured with the application ImageJ software version 1.46 r (Wayne Rasband, National Institutes of Health) and the values of root elongation were expressed in $\mathrm{mm}$.

Statistical analysis. The D'Agostino Pearson normality test $(\alpha=0.5)$ was performed on the root elongation data and, due to the abnormal distribution of the values of radicular elongation, the non-parametric Kruskall Wallis test with Dunn's post hoc test were applied in order to evaluate the statistical differences.

The inhibition (I\%) was calculated and plotted against the logarithm of concentrations and the corresponding curves were calculated using the least squares fit method. The inhibitory activity was defined as the concentration of compound (IC50) causing a $50 \%$ decrease in root length, relative to the solvent control, and was calculated using the equation presented in our previous study (9). The negative $\log 10$ values of the IC50 value expressed as a molar concentration (pIC50) were calculated for each tested compound. Whenever the obtained results permitted, the upper and lower limits of the $95 \%$ confidence interval $(95 \% \mathrm{CI})$ and the correlation coefficient $\left(\mathrm{r}^{2}\right)$ were calculated.

NCI uses a panel of 60 human tumor cell lines representing 9 tissue types (central nervous system, leukemia, breast, colon, renal, lung, ovary, prostate and melanoma) to screen novel synthesized compounds and pure natural products. In this study, we used negative $\log 10$ of the $50 \%$ growth inhibitory concentration expressed as molar concentration (pGI50) for each test compound. All data were collected freely from the DTP website (https://dtp.cancer. gov/databases_tools/default.htm). 
Table I. The inhibitory effect on wheat root elongation after $24 \mathrm{~h}$ of exposure to the anti-proliferative agents.

\begin{tabular}{|c|c|c|c|c|c|c|c|c|}
\hline \multirow[b]{3}{*}{ Compound } & \multicolumn{8}{|c|}{ Concentration $(\mu \mathrm{M})$} \\
\hline & 500 & 100 & 50 & 10 & 5 & 1 & 0.5 & 0.1 \\
\hline & \multicolumn{8}{|c|}{$\mathrm{I} \%$} \\
\hline Albendazole & 24.68 & 28.17 & 6.76 & 0.99 & 27.22 & 24.33 & 12.86 & NT \\
\hline Aminophylline & 53.04 & 32.63 & -14.74 & -24.60 & -16.68 & -41.23 & -18.33 & -3.06 \\
\hline Busulfan & 10.01 & 6.78 & 3.33 & 29.16 & 15.18 & 6.86 & 3.67 & -0.14 \\
\hline Cantharidin & NT & NT & 80.42 & 66.28 & 17.10 & 32.55 & -10.35 & 4.07 \\
\hline Chlorambucil & 4.09 & 0.24 & 17.92 & 14.20 & -1.67 & 19.72 & 21.53 & NT \\
\hline Cisplatin & 66.21 & 22.60 & 23.45 & -7.67 & 4.11 & 0.74 & 2.29 & -12.94 \\
\hline Colchicine & 88.03 & 85.53 & 81.14 & 17.40 & 22.04 & 16.21 & 15.90 & 2.71 \\
\hline Cyclophosphamide & 13.70 & 23.74 & 5.46 & 9.33 & -5.90 & -1.48 & -3.98 & -9.77 \\
\hline Epirubicin & 5.72 & 10.84 & -5.15 & -16.05 & -7.65 & -15.24 & -27.41 & -6.11 \\
\hline Fluorouracil & 7.70 & 17.89 & 38.19 & 8.42 & 12.56 & 15.97 & 3.16 & 22.85 \\
\hline Hydroxyurea & 15.05 & 7.35 & 24.88 & 6.70 & 15.62 & 11.23 & 17.66 & 4.90 \\
\hline Imatinib mesylate & 4.16 & -7.56 & 5.50 & 9.49 & 3.36 & 11.30 & 3.45 & NT \\
\hline Indole-3-acetic acid & NT & 71.08 & 42.34 & 25.41 & 11.31 & 11.79 & 12.85 & 16.43 \\
\hline Irinotecan & 35.28 & 4.73 & 11.33 & 4.42 & 33.79 & -1.16 & 17.90 & 19.20 \\
\hline Mercaptopurine & 14.22 & 10.12 & 23.01 & -4.83 & -2.72 & -10.09 & -7.00 & -1.67 \\
\hline Methotrexate & NT & NT & 94.39 & 88.82 & 58.75 & 39.36 & -15.71 & -16.63 \\
\hline Paclitaxel & 40.25 & 40.89 & 31.01 & 29.30 & 20.85 & 30.78 & 12.33 & 10.51 \\
\hline Podophyllotoxin & 44.80 & 24.71 & 35.69 & 28.00 & 20.26 & 19.38 & 34.55 & 1.46 \\
\hline Quinine & 10.23 & 20.32 & -4.92 & -11.57 & -28.97 & -25.35 & -14.12 & -52.48 \\
\hline Verapamil hydrochloride & 54.98 & 10.45 & -2.94 & -9.94 & -15.91 & -28.29 & -25.50 & -28.99 \\
\hline
\end{tabular}

I\%, inhibitory effect; NT, not tested.

A hierarchical cluster analysis of the root elongation inhibitory effects was performed using the furthest neighbor method and Euclidean distance measure. A two-sample t-test for unpaired data was performed to compare data sets.

\section{Results}

Triticum aestivum root elongation assay. A total of 18 anti-proliferative agents were selected based on their anti-proliferative mechanistic diversity and were tested in the Triticum aestivum root elongation assay. Aminophylline was selected as the negative control, having no significant effect on all NCI60 cell lines, as well as indole-3-acetic acid (https://dtp.cancer.gov/databases_tools/default.htm) selected as the control, since its effect on root elongation is well known. The values obtained for the inhibitory effects are presented in Table I. The values ranged from -41.23 , which represent a stimulation of root length, to an inhibition of $88.03 \%$.

As shown in Table II, the Kruskal Wallis test revealed statistically significant differences between the results obtained at various concentrations, although a linear effect-concentration association was not found for all determinations. No association was found between concentration and root elongation for albendazole, chlorambucil, hydroxyurea, imatinib and irinotecan. Dunn's post-test revealed statistically significant differences between the results obtained for each concentration and the solvent control sample, with the exception of quinine and verapamil, which induced a stimulating effect, without being statistically significant.

Even after exposure at high doses, only 5 of the anti-proliferative agents, methotrexate, colchicine, cantharidin, cisplatin and verapamil produced a growth inhibition over $50 \%$. Detecting only 5 out of the 18 anti-proliferative compounds tested suggests a poor predictive power and a high false-negative ratio. The inhibition threshold of $50 \%$ was also achieved for aminophylline and indole-3-acetic acid. For all these compounds, the half maximal inhibitory concentration (IC50) values and their corresponding negative logarithm (pIC50) were computed based on the dose-response curves presented in Fig. 1. The IC50 values, their corresponding confidence interval, and correlation coefficient $\left(\mathrm{r}^{2}\right)$ were calculated and are presented in Table III in ascending order.

The high rate of false-positives is due to the small tested set and the deliberate selection of indole-3-acetic acid as a known root growth inhibitor without an anti-proliferative effect. The most frequent problem observed was the low water solubility of some compounds that hindered testing on higher concentrations that would have produced an inhibition $>50 \%$. This is probably the main reason for the low sensitivity of the test.

Cluster analysis of the root elongation inhibitory effects. In order to better determine the wheat root inhibition profile of all the 20 tested substances, a hierarchical cluster analysis was performed using the furthest neighbor 
Table II. Statistical analysis of the root elongation.

Dunn's test

[concentration $(\mu \mathrm{M})]$

\begin{tabular}{|c|c|c|c|c|c|c|c|c|c|}
\hline & & & & & & & & & \\
\hline Compound & Kruskal-Wallis test & 500 & 100 & 50 & 10 & 5 & 1 & 0.5 & 0.1 \\
\hline Albendazole & $* * *$ & $* * *$ & $* * *$ & ns & ns & $* * *$ & $* * *$ & $*$ & NT \\
\hline Aminophylline & $* * *$ & $* * *$ & $*$ & ns & ns & ns & ns & ns & ns \\
\hline Busulfan & $* * *$ & $*$ & ns & $* * *$ & $* * *$ & $* * *$ & $* * *$ & $* * *$ & $*$ \\
\hline Cantharidin & $* * *$ & NT & NT & $* * *$ & $* * *$ & ns & $* *$ & ns & ns \\
\hline Chlorambucil & $* * *$ & ns & ns & $* * *$ & $* *$ & ns & $* * *$ & $* * *$ & NT \\
\hline Cisplatin & $* * *$ & $* * *$ & $* * *$ & $* * *$ & ns & ns & ns & ns & ns \\
\hline Colchicine & $* * *$ & $* * *$ & $* * *$ & $* * *$ & ns & $*$ & $*$ & ns & ns \\
\hline Cyclophosphamide & $* * *$ & $* * *$ & $* * *$ & $* * *$ & $* * *$ & $*$ & $* *$ & $* *$ & $*$ \\
\hline Epirubicin & $*$ & ns & ns & ns & ns & ns & ns & $* *$ & ns \\
\hline Fluorouracil & $* * *$ & ns & $* * *$ & $* * *$ & ns & $*$ & $*$ & ns & $* * *$ \\
\hline Hydroxyurea & $* * *$ & $*$ & ns & $* * *$ & $* *$ & $* * *$ & $* * *$ & $* * *$ & $* * *$ \\
\hline Imatinib & $* * *$ & ns & ns & $* *$ & ns & $* *$ & $* *$ & $*$ & NT \\
\hline Indole-3-acetic acid & $* * *$ & NT & $* * *$ & $* * *$ & $* *$ & ns & ns & ns & $*$ \\
\hline Irinotecan & $* * *$ & $* * *$ & ns & ns & ns & $* * *$ & ns & ns & $*$ \\
\hline Mercaptopurine & $* * *$ & $*$ & $*$ & $* * *$ & $*$ & $* *$ & $* *$ & $* *$ & $* *$ \\
\hline Methotrexate & $* * *$ & NT & NT & $* * *$ & $* * *$ & $* * *$ & $*$ & ns & ns \\
\hline Paclitaxel & $* * *$ & $* * *$ & $* * *$ & $* * *$ & $* * *$ & $*$ & $* * *$ & ns & ns \\
\hline Podophyllotoxin & $* * *$ & $* * *$ & $* * *$ & $* * *$ & $* *$ & $*$ & $*$ & $* * *$ & ns \\
\hline Quinine & $* * *$ & ns & ns & ns & ns & ns & ns & ns & $*$ \\
\hline Verapamil & $* * *$ & $* * *$ & ns & ns & ns & ns & ns & ns & ns \\
\hline
\end{tabular}

The values were calculated using the Kruskal-Wallis test with Dunn's post hoc test $(\alpha=0.05)$. NT, not tested. Statistical significance is denoted as follows: ns, not statistically significant $(\mathrm{P}>0.05)$; a single asterisk $(*)$ indicates $\mathrm{P}<0.05$; double asterisks $(* *)$ indicate $\mathrm{P}<0.01$; and triple asterisks (***) indicate $\mathrm{P}<0.001$.

method and Euclidean distance measure. Three major clusters were obtained (Fig. 2). The first is represented by colchicine, methotrexate, cantharidin and indole-3-acetic acid as the group of potent root elongation inhibitors; the second comprises epirubicin, quinine, verapamil, and aminophylline, compounds with a stimulatory effect at low concentrations and an inhibitory effect at larger doses. The third group contains compounds with low inhibitory effects: cisplatin, podophyllotoxin, paclitaxel, irinotecan, albendazole, busulfan, imatinib, chlorambucil, mercaptopurine, cyclophosphamide, hydroxyurea and fluorouracil.

Cluster analysis of the NCI60 anti-proliferative profile. All anticancer agents tested in the Triticum assay were statistically analyzed based on their anti-proliferative pattern registered in the NCI60 human tumor cell line anticancer drug screen. Indole-3-acetic acid was not included in the classification as it was not tested in the NCI60 5-dose screening. The NCI60 5-dose assay results in a characteristic fingerprint of cellular response that can be used to assign a mechanism of action, or to classify the compounds. NCI defines the half maximal growth inhibition (GI50) as the molar concentration that causes $50 \%$ inhibition for each cell line, and pGI50 as the negative logarithm of GI50. The pGI50 values were selected as the end-point for this study.
The anti-proliferative effect of a compound on a single cell line offers little information, but an array of effects across the 60 cell lines gives important strength to the method. All tested compounds were hierarchically clustered using the furthest neighbor approach and the Euclidean distance measure on the 60x19 matrix of pGI50 values (Fig. 3).

The patterns of growth inhibition in the NCI60 5-dose assay have been used in a number of studies to identify the mechanism for new compounds, or to better determine their effects on specific oncologic targets $(29,31,33)$. The results of our classification produced different clusters than the results of Triticum root assay, but some interesting similarities can be pointed out.

In both human and plant cells, methotrexate and colchicine demonstrated comparable profiles. Paclitaxel and podophyllotoxin produced similar profiles in human cells and in the root elongation test, in concordance with the known mechanism of disrupting microtubule/tubulin dynamics. Paclitaxel binds to polymerized microtubules and promotes tubulin stabilization, while podophyllotoxin induces microtubule depolymerization (34). Colchicine presented the same mechanism as podophyllotoxin; however, of note, the anti-proliferative profile of the two compounds correlated only in the human cells, while in the root cells its correlated better with methotrexate. A good correlation of the colchicine and methotrexate cell susceptibility can also be observed in the NCI60 data. 
A

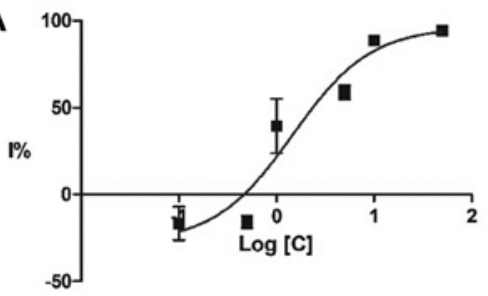

C

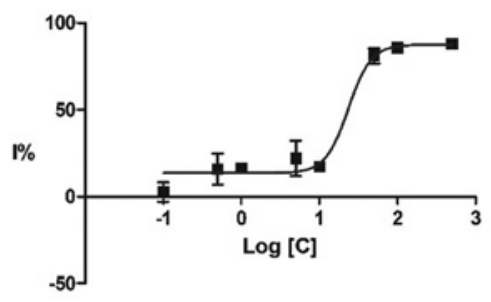

E

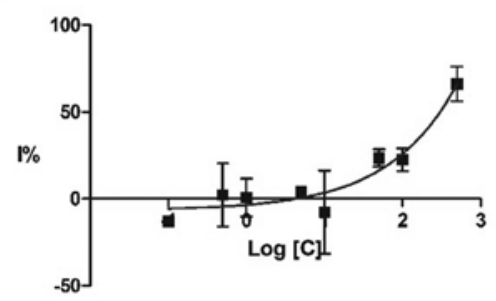

G

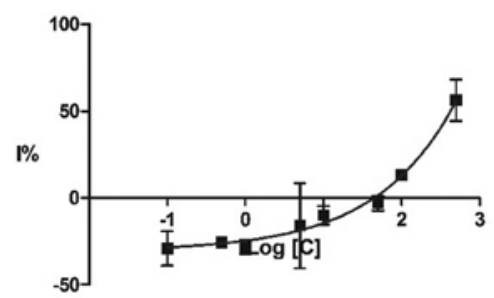

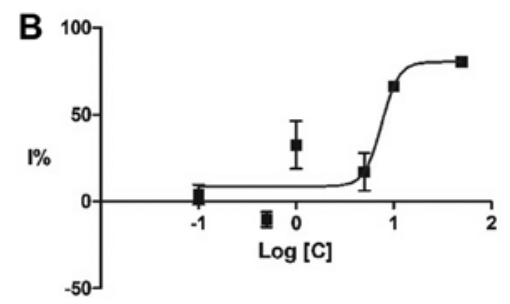

D

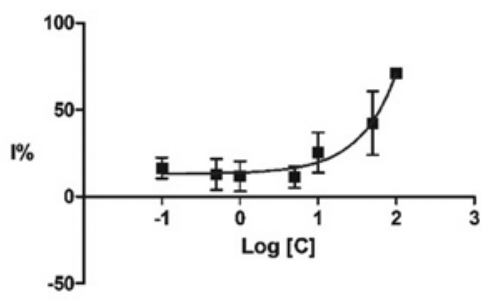

$\mathbf{F}$

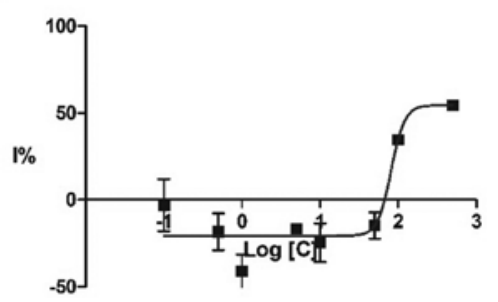

Figure 1. Inhibition curves of wheat root elongation following treatment for $24 \mathrm{~h}$ with: (A) methotrexate, (B) cantharidin, (C) colchicine, (D) indole-3-acetic acid, (E) cisplatin, (F) aminophylline, and (G) verapamil. I\%, inhibitory effect.

Correlation of Triticum test results and NCI60 anti-proliferative profile. Methotrexate had the optimal inhibitory effect on the Triticum assay, with a pIC50 value of -5.526 (Table III), compared to the values registered on human cancer cells, ranging from -6.106 to -9.000 , with an average value of -7.895 (data not shown). Cantharidin also produced a potent inhibitory effect on root elongation, with a pIC50 value of -5.039 , but closer to those in human cells where the average was -5.780 . In the case of colchicine the pIC50 was -4.684 , significantly higher than the average value calculated for the human cells as -7.211 (data not shown). For all these compounds, as well as cisplatin and verapamil, the inhibitory effect on the Triticum test was registered at a higher concentration than those noted on human cells. In the case of aminophylline, the results could not be compared as the NCI60 assay protocol begins with the highest concentration of $10^{-4} \mathrm{M}$ and the pGI50 values can be anywhere above the -4 threshold.

The calculated pIC50 values were used to compare the Triticum assay with the array of pGI50 values for all human tumor cells from the NCI60 panel, in order to identify whether the root elongation test correlates with a particular type of tumor cell. The statistical analysis was performed for the methotrexate, cantharidin, colchicine, cisplatin, aminophylline and verapamil data arrays on Triticum against each cell line of the NCI60 panel. Indole-3-acetic acid was not used as the pGI50 values are not registered on the NCI database. The correlation was significant at the 0.05 level (2-tailed). Of all the 60 cell lines, a significant correlation was registered for only 12 cell lines. Plotting the 6 pGI50 values against the IC50, a conversion equation was computed that can be used for the prediction of the anti-proliferative effect on those cells based on the Triticum assay (Table IV). 
Table III. The inhibitory effect on root elongation following $24 \mathrm{~h}$ of exposure.

\begin{tabular}{lcccc}
\hline Compound & IC50 $(\mu \mathrm{M})$ & pIC50 $(\mathrm{M})$ & 95\% CI of IC50 $(\mu \mathrm{M})$ & Goodness of fit $\left(\mathrm{r}^{2}\right)$ \\
\hline Methotrexate & 2.978 & -5.526 & 0.042 to 51.35 & 0.9177 \\
Cantharidin & 9.141 & -5.039 & 1.210 to 46.87 & 0.8254 \\
Colchicine & 20.70 & -4.684 & 8.651 to 63.31 & 0.9668 \\
Indole-3-acetic acid & 49.204 & -4.308 & NC & 0.8711 \\
Cisplatin & 263.633 & -3.579 & NC & 0.8206 \\
Aminophylline & 409.261 & -3.388 & 41.92 to 160.8 & 0.8560 \\
Verapamil & 441.570 & -3.355 & NC & 0.9156 \\
\hline
\end{tabular}

NC, could not be calculated due to the results obtained; $\mathrm{r}^{2}$, correlation coefficient.

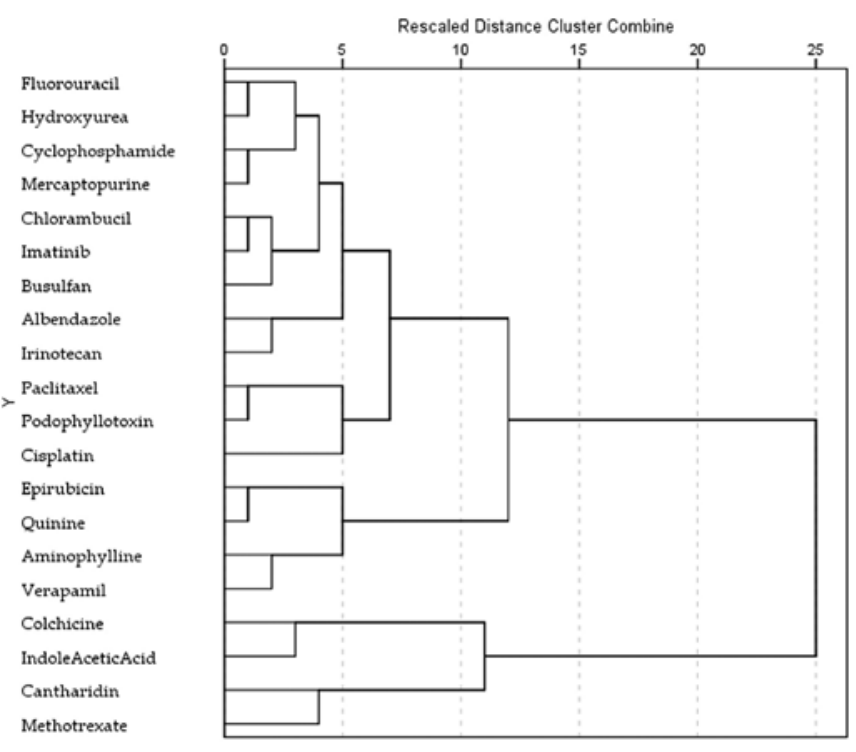

Figure 2. Dendrogram cluster of the tested compounds based on their root inhibitory effect using the complete linkage method.

The results indicated a similar effect of the tested 6 drugs on the wheat root elongation and on 12 human cancer cell lines, representing 6 of the 9 tissue types of the NCI60 panel. There seemed to be no association between the cell origin and the existence of a correlation with the Triticum test. We defined these 12 cell lines as the Triticum cell panel. Comparing these cell lines with those uncorrelated in order to illustrate the interdependence factors, a simple observation was made that the cells doubling times were smaller in the Triticum cell panel, with an average of $25.2 \mathrm{~h}$, compared to $37.45 \mathrm{~h}$ in the rest of the cells (data not shown). A two-sample t-test for unpaired data was performed and demonstrated a significant difference $(\mathrm{P}<0.01)$ between the two set doubling times. In addition, cells such as HOP-92, NCI-H226, or A498, which have a doubling time over $60 \mathrm{~h}$, share a Pearson's coefficient under 0.5 with the IC50 array of values (data not shown).

Table IV describes 12 linear equations that can be used to transform the IC50 value calculated in any future Triticum assay in order to predict the pGI50 value of the Triticum cells panel. For all these cells, the computed equations indicate higher pGI50 values, compared with the IC50 value, arguing to a higher resistance of the wheat root cells to the effect of the

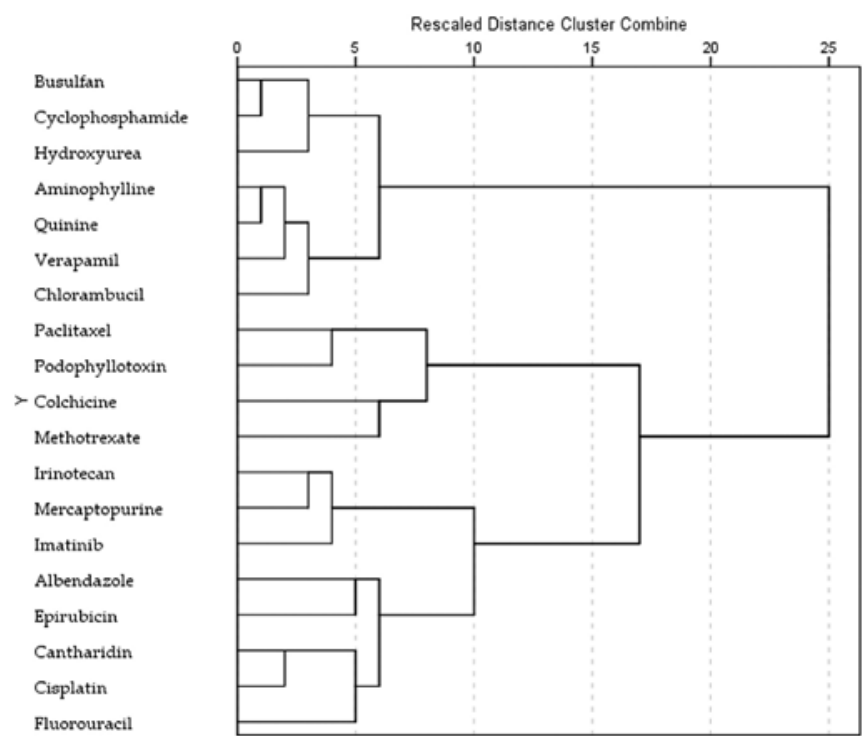

Figure 3. Dendrogram cluster using the complete linkage method based on their pGI50 values in the NCI60 assay.

anticancer drugs. These equations could be reversed to evaluate the environmental impact of antineoplastic drugs on higher plants.

\section{Discussion}

The Triticum root elongation test is a simple and inexpensive method for screening novel chemical compounds; however, its use is often empirical. The aim of this study was to validate this method for assessing the anti-proliferative effects of synthetic or natural compounds and to use it as an alternative technique.

The results indicated that when used on its own, the Triticum test is not a very good choice for the selection of novel anti-proliferative compounds, due to the high false-negative ratio. Of the tested 18 anti-proliferative agents, only 5 were identified as inhibitors of root elongation.

Methotrexate registered the highest impact on the Triticum root. It is one of the earliest anticancer drugs, an antifolate that mainly inhibits dihydrofolate reductase, leading to impaired purine synthesis. As a result, malignant cells are unable to synthesize DNA and RNA, leading to cell apoptosis (35). 
Table IV. Correlation of the Triticum assay with the anti-proliferative effects of selected drugs.

\begin{tabular}{|c|c|c|c|c|c|c|}
\hline Cell ID & Cell line & Tissue type & Pearson's correlation & Sig. (2-tailed) & Conversion equation & $r^{2}$ \\
\hline 1004 & A549 & Non-small cell lung & 0.878 & 0.021 & $1.358 * x+0.103$ & 0.771 \\
\hline 4003 & НCT-116 & Colon & 0.839 & 0.037 & $1.533 * x+0.565$ & 0.703 \\
\hline 4015 & HCT-15 & Colon & 0.833 & 0.039 & $1.224 * x-0.299$ & 0.694 \\
\hline 7003 & CCRF-CEM & Leukemia & 0.813 & 0.049 & $1.397 * x+0.143$ & 0.661 \\
\hline 7005 & K-562 & Leukemia & 0.832 & 0.040 & $1.605^{*} \mathrm{x}+0.886$ & 0.693 \\
\hline 9008 & SN12C & Renal & 0.829 & 0.041 & $1.273 * \mathrm{x}-0.221$ & 0.688 \\
\hline 9018 & $786-0$ & Renal & 0.859 & 0.028 & $1.404 * x+0.272$ & 0.738 \\
\hline 9023 & $\mathrm{ACHN}$ & Renal & 0.893 & 0.017 & $1.258 * \mathrm{x}-0.187$ & 0.798 \\
\hline 11001 & PC-3 & Prostate & 0.922 & 0.009 & $1.719 * x+1.282$ & 0.850 \\
\hline 11003 & DU-145 & Prostate & 0.853 & 0.031 & $1.128 * x-0.509$ & 0.728 \\
\hline 12009 & $\mathrm{U} 251$ & Central nervous system & 0.826 & 0.043 & $1.333^{*} \mathrm{x}-0.075$ & 0.683 \\
\hline 12014 & SF-268 & Central nervous system & 0.882 & 0.020 & $1.233 * x-0.259$ & 0.777 \\
\hline
\end{tabular}

$\mathrm{r}^{2}$, correlation coefficient.

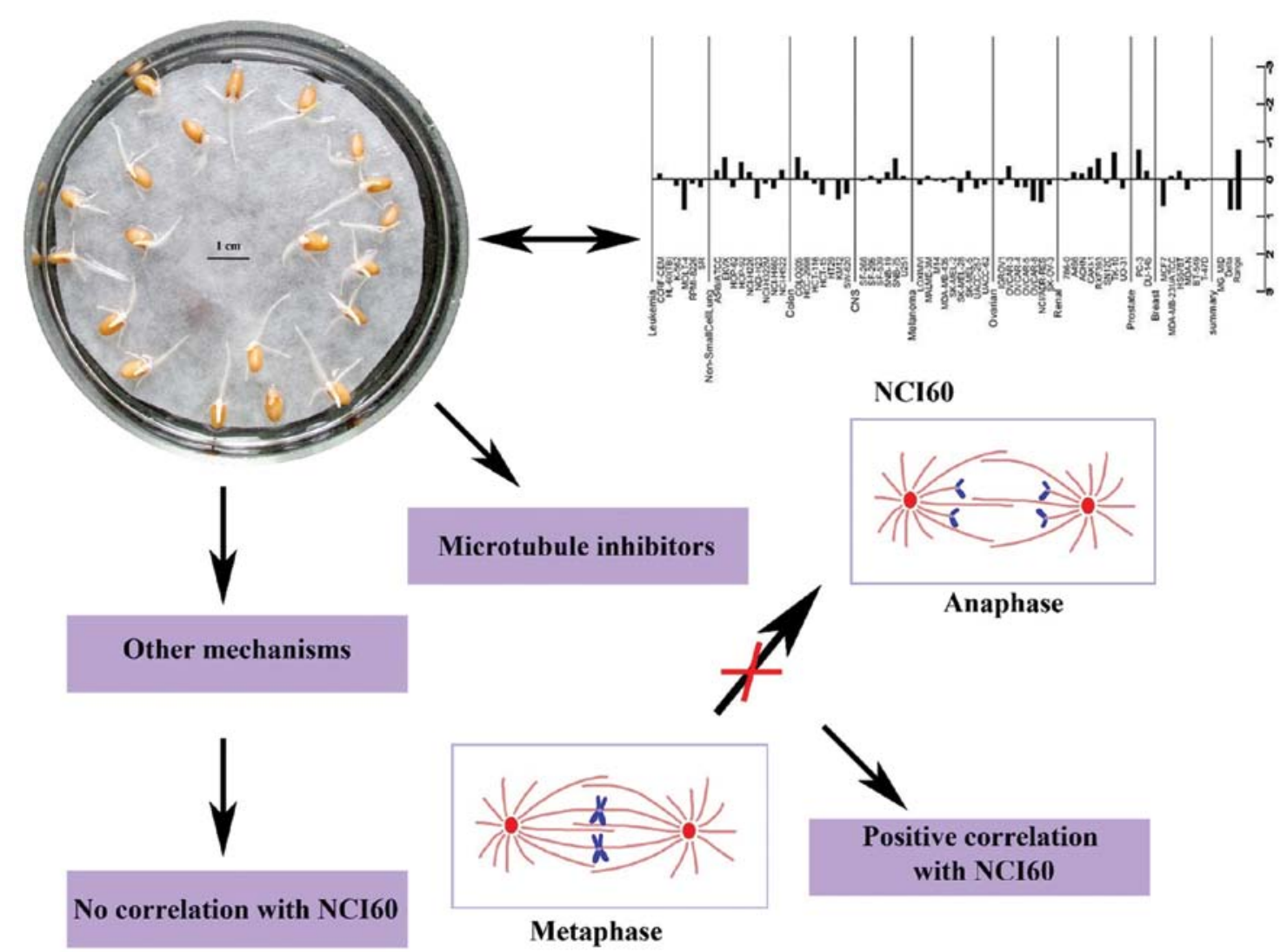

Figure 4. The mechanisms of the correlation between the Triticum root elongation data and the NCI60 cell anti-proliferative profile.

This confirms the findings of previous studies emphasizing the crucial role of folates in root development $(36,37)$. Cantharidin is a natural substance, secreted by blister beetles, particularly Lytta vesicatoria, which inhibits protein phosphatase 2A. Protein phosphatases are involved in multiple cellular processes, although the exact pathway through which they exert growth inhibitory effects and cell death remains unclear (38). This study indicated a similar pattern of response for cantharidin and methotrexate in plants, but different in human cells.
Colchicine, podophyllotoxin and paclitaxel belong to the larger group of spindle assembly inhibitors or spindle poisons, compounds that interrupt the mitosis phase of cell division (25). Previous studies have indicated that cantharidin also disrupts the organization of spindles, resulting in a prolonged mitotic arrest $(38,39)$. In this study, all these compounds inhibited root elongation, indicating that the Triticum root assay can effectively detect drugs acting as mitotic inhibitors (Fig. 4).

Cisplatin induces cytotoxicity by interfering with DNA repair mechanisms, causing DNA damage and inducing the 
apoptosis of cancer cells (40). Cisplatin has a very similar mechanism as busulfan, chlorambucil and cyclophosphamide $(41,42)$; however, these compounds had little effect on root elongation. The most probable explanation is their low potency on human cancer cells.

The Triticum test can be helpful for future research, particularly if is coupled with some simple tests to evaluate the toxicological profile of a new compound or plant extract, such as the Daphnia assay (43-45). A high inhibitory effect on the root elongation combined with a low toxic effect can be a good indicator of an anti-proliferative effect on the cell lines described as the Triticum panel. Using the conversion functions presented herein, a good estimation of the GI50 value can be obtained. The repurposing of plants herbicides as potential anticancer leads can be an important future direction to use the Triticum test. Phosphinothricin is such an example emerging as a novel anticancer agent against MCF-7 breast cancer and A549 lung cancer cell lines (46).

The results of this study suggested that the Triticum root elongation test can detect several types of anti-proliferative mechanisms, as described above, particularly those targeting tubulin. Triticum assay may be an effective good tool which could be used to identify novel spindle inhibitors. Some studies (mentioned above) have reported the possibility of repurposing known herbicides as cytotoxic agents.

In conclusion, the findings of the present study demonstrate that the Triticum root elongation assay is a simple and inexpensive method when used empirically for the screening of novel chemical compounds. The results indicate that on its own, the Triticum test is not a very good choice for the selection of novel anti-proliferative compounds, due to the high false-negative ratio; however, it can be useful if coupled with simple tests that can evaluate the toxicological profile. This study indicates that the Triticum assay may prove to be a good tool which could be used to identify novel spindle inhibitors and for the repurposing of plant herbicides as potential anticancer agents. It may prove to be an important assay for future research direction.

\section{Acknowledgements}

Not applicable.

\section{Funding}

This study was financially supported by the 'Carol Davila' University of Medicine and Pharmacy through Contract no. 23PFE/17.10.2018 funded by the Ministry of Research and Innovation within PNCDI III, Program 1-Development of the National RD system, Subprogram 1.2-Institutional Performance-RDI excellence funding projects.

\section{Availability of data and materials}

Data sharing is not applicable to this article, as no datasets were generated or analyzed during the current study.

\section{Authors' contributions}

OTO and GMN were involved in the conceptualization of the study. CEDP was responsible for funding acquisition. OTO,
AZ, GMN, GN, CEDP, VA, AT, DAS, DM and OCS were all involved in the study methodology, in writing, review and editing of the manuscript. All authors have read and approved the final manuscript.

\section{Ethics approval and consent to participate}

Not applicable.

\section{Patient consent for publication}

Not applicable.

\section{Competing interests}

DAS is the Editor-in-Chief for the journal, but had no personal involvement in the reviewing process, or any influence in terms of adjudicating on the final decision, for this article. The other authors declare that they have no competing interests. The founding sponsors had no role in the design of the study, or in the collection, analyses, or interpretation of the data, or in the writing of the manuscript, and in the decision to publish the results.

\section{References}

1. Festing $\mathrm{S}$ and Wilkinson R: The ethics of animal research. Talking point on the use of animals in scientific research. EMBO Rep 8: 526-530, 2007.

2. Mak IWY, Evaniew N and Ghert M: Lost in translation: Animal models and clinical trials in cancer treatment. Am J Transl Res 6: 114-118, 2014.

3. North $M$ and Vulpe CD: Functional toxicogenomics: Mechanism-centered toxicology. Int J Mol Sci 11: 4796-4813, 2010.

4. Gatehouse D: Bacterial mutagenicity assays: Test methods. In: Genetic Toxicology: Principles and Methods. Parry JM and Parry EM (eds.) Springer New York, New York, NY, pp21-34, 2012.

5. Bagur-González MG, Estepa-Molina C, Martín-Peinado F and Morales-Ruano S: Toxicity assessment using Lactuca sativa $\mathrm{L}$. bioassay of the metal(loid)s $\mathrm{As}, \mathrm{Cu}, \mathrm{Mn}, \mathrm{Pb}$ and $\mathrm{Zn}$ in soluble-in-water saturated soil extracts from an abandoned mining site. J Soils Sediments 11: 281-289, 2011.

6. Czerniawska-Kusza I, Ciesielczuk T, Kusza G and Cichoń A: Comparison of the Phytotoxkit microbiotest and chemical variables for toxicity evaluation of sediments. Environ Toxicol 21: 367-372, 2006

7. Sánchez-Meza J, Pacheco-Salazar V, Pavón-Silva T, Guiérrez-García V, Avila-González CJ and Guerrero-García P: Toxicity assessment of a complex industrial wastewater using aquatic and terrestrial bioassays Daphnia pulex and Lactuca sativa. J Env Sci Heal A Tox Hazard Subst Env Eng 42: 1425-1431, 2007.

8. Pandard P, Devillers J, Charissou AM, Poulsen V, Jourdain MJ, Férard JF, Grand C and Bispo A: Selecting a battery of bioassays for ecotoxicological characterization of wastes. Sci Total Environ 363: 114-125, 2006.

9. Guțu CM, Olaru OT, Purdel CN, Ilie M and Diacu E: Phytotoxicity of inorganic arsenic assessed by Triticum test. Rev Chim 66: 333-335, 2015.

10. Ahmed FAW: Cytotoxic and genotoxic potency screening of WIDE-SPEC pesticide on Allium cepa L. root meristem cells. J Nat Sci Res 4: 100-108, 2014.

11. Dragoeva A, Koleva V, Hasanova N and Slanev S: Cytotoxic and genotoxic effects of diphenyl-ether herbicide GOAL (Oxyfluorfen) using the Allium cepa test. Res J Mutagen 2: 1-9, 2012.

12. Seremet OC, Olaru OT, Ilie M, Negres S and Balalau D: Phytotoxicity assessment of certain phytochemical products containing pyrrolizidine alkaloids. Acta Med Marisiensis 59: 250-253, 2013 . 
13. Lee WM, An YJ, Yoon $\mathrm{H}$ and Kweon HS: Toxicity and bioavailability of copper nanoparticles to the terrestrial plants mung bean (Phaseolus radiatus) and wheat (Triticum aestivum): Plant agar test for water-insoluble nanoparticles. Environ Toxicol Chem 27: 1915-1921, 2008.

14. Ashrafi ZY, Sadeghi S and Mashhadi HR: Inhibitive effects of barley (Hordeum vulgare) on germination and growth of seedling quack grass (Agropyrum repens). Icel Agric Sci 22: 37-43, 2009.

15. Yuet Ping K, Darah I, Yusuf UK, Yeng C and Sasidharan S: Genotoxicity of Euphorbia hirta: An Allium cepa assay. Molecules 17: 7782-7791, 2012.

16. Pawlowski Â, Kaltchuk-Santos E, Zini CA, Caramão EB and Soares GLG: Essential oils of Schinus terebinthifolius and S. molle (Anacardiaceae): Mitodepressive and aneugenic inducers in onion and lettuce root meristems. S Afr J Bot 80: 96-103, 2012

17. Diaz Napal GN and Palacios SM: Phytotoxicity of secondary metabolites isolated from Flourensia oolepis S.F.Blake. Chem Biodivers 10: 1295-1304, 2013

18. Furmanowa M, Guzewska J and Bełdowska B: Mutagenic effects of aqueous extracts of Symphytum officinale L. and of its alkaloidal fractions. J Appl Toxicol 3: 127-130, 1983.

19. Zasada IA, Klassen W, Meyer SL, Codallo M and Abdul-Baki AA: Velvetbean (Mucuna pruriens) extracts: Impact on Meloidogyne incognita survival and on Lycopersicon esculentum and Lactuca sativa germination and growth. Pest Manag Sci 62: 1122-1127, 2006.

20. Andrade-Vieira LF, Botelho CM, Laviola BG, Palmieri MJ and Praça-Fontes MM: Effects of Jatropha curcas oil in Lactuca sativa root tip bioassays. An Acad Bras Cienc 86: 373-382, 2014.

21. Stampoulis D, Sinha SK and White JC: Assay-dependent phytotoxicity of nanoparticles to plants. Environ Sci Technol 43: 9473-9479, 2009.

22. Jităreanu A, Pădureanu S, Tătărîngă G, Tuchilus GC and Stănescu U: Evaluation of phytotoxic and mutagenic effects of some cinnamic acid derivatives using the Triticum test. Turk J Biol 37: 748-756, 2013.

23. Radić S, Stipaničev D, Vujcić V, Rajcić MM, Širac S and Pevalek-Kozlina B: The evaluation of surface and wastewater genotoxicity using the Allium cepa test. Sci Total Environ 408: 1228-1233, 2010.

24. Beemster GTS and Baskin TI: Analysis of cell division and elongation underlying the developmental acceleration of root growth in Arabidopsis thaliana. Plant Physiol 116: 1515-1526, 1998.

25. Komlodi-Pasztor E, Sackett DL and Fojo AT: Inhibitors targeting mitosis: Tales of how great drugs against a promising target were brought down by a flawed rationale. Clin Cancer Res 18: 51-63, 2012.

26. Chabner BA: NCI-60 Cell Line Screening: A radical departure in its time. Natl Cancer Inst 108: pii: djv388, 2016.

27. Devinyak O, Havrylyuk D, Zimenkovsky B and Lesyk R: Computational search for possible mechanisms of 4-thiazolidinones anticancer activity: The power of visualization. Mol Inform 33: 216-229, 2014.

28. Soriga SG, Plesu V, Marton A, Bonet-Ruiz J, Marton GI and Iancu P: Small computer clusters for molecular modelling. Rev Chim 65: 960-965, 2014.

29. Khan SA, Virtanen S, Kallioniemi OP, Wennerberg K, Poso A and Kaski S: Identification of structural features in chemicals associated with cancer drug response: A systematic data-driven analysis. Bioinformatics 30: i497-i504, 2014.

30. Nitulescu GM, Soriga SG, Socea LI, Olaru OT and Plesu V: Structure-activity relationships and chemoinformatic analysis of the anticancer profile of an aminopyrazole derivative. Rev Chim 67: 162-165, 2016.

31. Nitulescu GM, Iancu G, Nitulescu G, Iancu RC, Bogdanici C and Vasile D: Brave new hope for breast cancer: Aminopyrazole derivates between rational design and clinical efficacy. Rev Chim 68: 754-757, 2017.
32. Fu SF, Wei JY, Chen HW, Liu YY, Lu HY and Chou JY: Indole-3-acetic acid: A widespread physiological code in interactions of fungi with other organisms. Plant Signal Behav 10: e1048052-e1048052, 2015.

33. Nitulescu GM, Soriga SG, Socea LI, Olaru OT and Plesu V: Structure-activity relationships and chemoinformatic analysis of the anticancer profile of an aminopyrazole derivative. Rev Chim 67: 162-165, 2016.

34. Lu Y, Chen J, Xiao M, Li W and Miller DD: An overview of tubulin inhibitors that interact with the colchicine binding site. Pharm Res 29: 2943-2971, 2012.

35. Papachristou M, Kastis GA, Stavrou PZ, Xanthopoulos S, Furenlid LR, Datseris IE and Bouziotis P: Radiolabeled methotrexate as a diagnostic agent of inflammatory target sites: A proof-of-concept study. Mol Med Rep 17: 2442-2448, 2018.

36. Giordano D, Reyneri A and Blandino M: Folate distribution in barley (Hordeum vulgare L.), common wheat (Triticum aestivum L.) and durum wheat (Triticum turgidum durum Desf.) pearled fractions. J Sci Food Agric 96: 1709-1715, 2016.

37. Gorelova V, Ambach L, Rébeillé F, Stove C and Van Der Straeten D: Folates in plants: Research advances and progress in crop biofortification. Front Chem 5: 21, 2017.

38. Liu Y-P, Li L, Xu L, Dai E-N and Chen WD: Cantharidin suppresses cell growth and migration, and activates autophagy in human non-small cell lung cancer cells. Oncol Lett 15: 6527-6532, 2018.

39. Bonness K, Aragon IV, Rutland B, Ofori-Acquah S, Dean NM and Honkanen RE: Cantharidin-induced mitotic arrest is associated with the formation of aberrant mitotic spindles and lagging chromosomes resulting, in part, from the suppression of PP2Aalpha. Mol Cancer Ther 5: 2727-2736, 2006.

40. Sun Y, Jiang W, Lu W, Song M, Liu K, Chen P, Chang A Ling J, Chiao PJ, Hu Y, et al: Identification of cisplatin sensitizers through high-throughput combinatorial screening. Int $\mathbf{J}$ Oncol 53: 1237-1246, 2018.

41. Dasari S and Tchounwou PB: Cisplatin in cancer therapy: Molecular mechanisms of action. Eur J Pharmacol 740: 364-378, 2014.

42. Florea AM and Büsselberg D: Cisplatin as an anti-tumor drug: Cellular mechanisms of activity, drug resistance and induced side effects. Cancers (Basel) 3: 1351-1371, 2011.

43. Pahontu E, Socea LI, Barbuceanu SF, Autor Nou, Olaru Octavian-Tudorel, Gulea Aurelian and Socea Bogdan: Synthesis, characterization and toxicity evaluation of $\mathrm{Cu}(\mathrm{II})$, $\mathrm{Mn}(\mathrm{II}), \mathrm{Co}(\mathrm{II}), \mathrm{Ni}(\mathrm{II}), \mathrm{Pd}(\mathrm{II})$ complexes with ligand derived from hydrazinecarbothioamide. Rev Chim 69: 2959-2963, 2018.

44. Nitulescu G, Nicorescu IM, Olaru OT, Ungurianu A, Mihai DP, Zanfirescu A, Nitulescu GM and Margina D: Molecular docking and screening studies of new natural sortase A inhibitors. Int J Mol Sci 18: 18, 2017.

45. Socea LI, Barbuceanu SF, Socea B, Draghici C, Apostol TV, Pahontu EM and Olaru OT: New heterocyclic compounds from 1,2,4-triazoles class with potential cytotoxic activity. Rev Chim 68: 2503-2508, 2017.

46. Sakr MT, Khedr AM, Rashed MH and Mohamed EM: In silico-based repositioning of phosphinothricin as a novel technetium-99m imaging probe with potential anti-cancer activity. Molecules 23, pii: E496, 2018.

This work is licensed under a Creative Commons Attribution-NonCommercial-NoDerivatives 4.0 International (CC BY-NC-ND 4.0) License. 